\title{
Analysis of Novel Phase-Shifted Full-Bridge Converters with Wide ZVS range Reduced Filter Requirement
}

\author{
Jiahui Cai ${ }^{1}$, Lei Zhao ${ }^{1}$, Chuliang Wei ${ }^{1 a)}$, and Jiawei Liang ${ }^{1}$
}

Abstract In this paper, some novel converters are proposed to solve the drawbacks of traditional phase-shifted full-bridge (PSFB) converter. In the primary side of proposed converters, the FB inverter is divided into two half-bridge inverters and the large-sized transformer is replaced by two small-sized transformers. By employing this structure, the zero voltage switching range can be extended and the primary circulating current existing in the additional PSFB converter is removed. In the secondary side, various rectifiers can be adopted to suit for different applications. Moreover, the primary power can be continuously transferred to secondary side in the proposed converters, which contributes to the reduction of output filter requirement. The circuit configuration, operational principle and relevant analysis of proposed converters are introduced in this paper. Experimental results on two typical prototype converters are built to validate the theoretical analysis.

key words: full-bridge converter, zero voltage switching (ZVS), circulating current, filter requirement

Classification: Power devices and circuits

\section{Introduction}

The phase-shifted full-bridge (PSFB) converter is the most widely adopted topology for high-power isolated DC-DC power conversion due to its simplicity and efficiency [1-6]. In the primary side of PSFB converter, four switches are controlled with phase-shifted modulation method, which makes it possible to achieve zero-voltage switching (ZVS) without the help of any auxiliary circuits [7-10]. The secondary structure consists of a rectifier and LC filter. Generally, the loss of rectifier is the main contributor to the total power loss of PSFB converter. Thus, different rectifier such as full-bridge rectifier (FBR) [11-13], center-tapped rectifier (CTR) [14-16] and current doubler rectifier (CDR) [17-20] can be applied to suit for various applications. In the FBR structure, there are only two secondary winding, which leads to lower transformer volt-ampere requirement and voltage stress but it takes high conduction loss. As for

\footnotetext{
${ }^{1}$ Department of Electrical Engineering, Shantou University, Guangdong, PT China
}

a)clwei@stu.edu.cn

DOI: 10.1587/elex.18.20210391

Received September 16, 2021

Accepted September 22, 2021

Publicized October 12, 2021 the CTR structure, during the transfer of power, only one diode conducts so it can take less conduction loss. However, the structure of transformer is complex and the voltage stress of diode is high. The winding structure of the CDR is simple and has few diodes at the same time, so it is preferred to be used in low-voltage high-current applications.

However, the traditional PSFB converter has some serious problems such as narrow ZVS range and primary circulating current. At light loads, the lagging switches lose ZVS and the conversion efficiency is severely degraded. In addition, the primary voltage is zero but the primary current is non-zero and this current just circulates in the primary side without transferring any power to the secondary side during the freewheeling interval. It causes excessive conduction loss and increased output filter requirement.

In order to solve the aforementioned problems and improve the performance of PSFB converter, many novel FB converters have been researched in the literature. The ZVS range can be extended by increasing the leakage inductance of main transformer. However, this method results in high duty-cycle loss and primary conduction loss. In [21-23], some novel PSFB converters with auxiliary circuits are proposed. The ZVS energy is independent of load current in these converters. Thus, primary switches can achieve ZVS under all operating conditions. But the primary circulating current still exists. It can be significantly reduced by utilizing the technology of zero-voltage and zero-current switching (ZVZCS) [24-26]. The primary current is reset by the introduced auxiliary circuits and it is maintained at zero during the freewheeling interval. The output power is maintained constant by the energy stored in the output filter, thus large filter requirement is required in these ZVZCS converters.

Recently, the PSFB converters with dual transformer are very attractive due to their outstanding performance [27-31]. Fig.1 shows two typical converters with FBR [28] and CTR [29]. As shown in Fig.1, the FB inverter is divided into a leading half-bridge (HB) and a lagging HB in the primary side. Compared to the traditional PSFB converters, these converters can achieve the following advantages: (1) All switches can achieve ZVS operation 
IEICE Electronics Express, Vol.xx, No.xx, xx-xx

under entire load conditions; (2) The conduction loss is greatly improved since the circulating current is fully eliminated in the proposed converter; (3) The primary power can be continually transferred to the secondary side, so the requirement of output filter is significantly reduced.

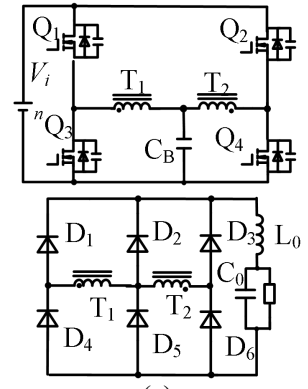

(a)

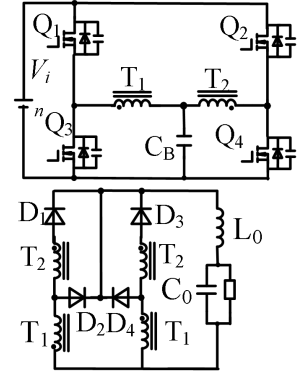

(b)
Fig. 1 Typical converters with (a) FBR [28] and (b) CTR [29].

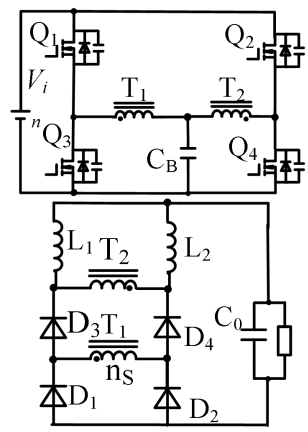

(a)

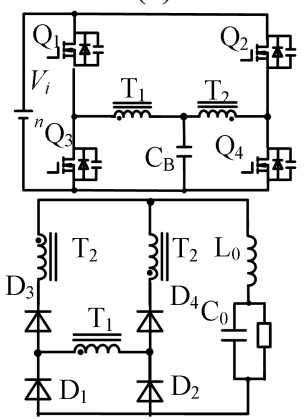

(c)

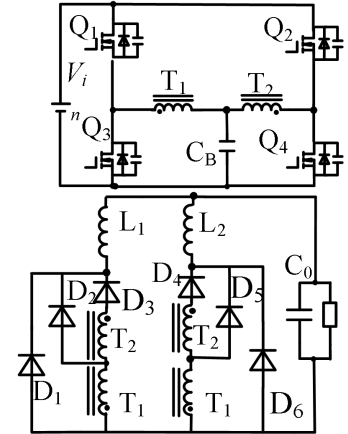

(b)

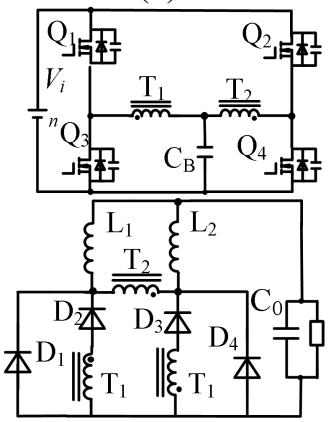

(d)
Fig. 2 Proposed converters with different rectifiers:(a) Converter \#1; (b) Converter \#2; (c) Converter \#3; (d) Converter \#4.

In order to enrich the family of PSFB converters with dual transformer, this paper proposes some novel typologies, as shown in Fig.2. In these converters, the primary structure is fixed but various rectifiers can be adopted in the secondary side. Fig.2(a) and Fig.2(b) show the converters with different CDR. The hybrid rectifier (Hyb-R) is composed of a CTR section and a FBR section. It is adopted in Fig.2(c) and Fig.2(d). These typologies allow the proposed converters to have the advantages of wide ZVS range and reduced filter requirement. This paper is organized as follows. As an example, the operational principle of proposed converter with CDR is presented in Section II. The relevant analysis and experimental results are described in Section III and Section IV, respectively. Finally, Section $\mathrm{V}$ concludes this paper.

\section{Operational Principle}

One of the proposed converters, as shown in Fig.2(a) is taken as an example to verify the feasibility. In order to illustrate the operation principle, several assumptions are made as follows: (1) the blocking capacitor $C_{B}$ and the output inductors $L_{1} \& L_{2}$ are large enough to be considered as constant voltage source of $0.5 V_{\text {in }}$ and current source of $0.5 I_{o}$, respectively; (2) the primary switches are ideal MOSFETs with body diodes and parasitic capacitors; (3) the leakage inductances of $T_{1}$ and $\mathrm{T}_{2}$ are $L_{k 1}$ and $L_{k 2}$, respectively; (4) the magnetizing inductance of the $\mathrm{T}_{2}$ is $L_{m}$.

Fig.3 shows the simplified equivalent circuit with current and voltage notations. The phase-shifted control method is employed in the proposed converter. The key operational waveform can be obviously acquired by using PSIM software. Based on the simulation results, the key waveforms of Converter \#1 can be shown in Fig.4 In the analysis, $T_{\alpha}$ indicates the shifted time between the leading-leg and the lagging-leg. On account of the symmetric structure of the converter, only the first half cycle is detailed in this article and the corresponding equivalent circuits are shown in Fig.5. The operating states can be divided into the following parts.

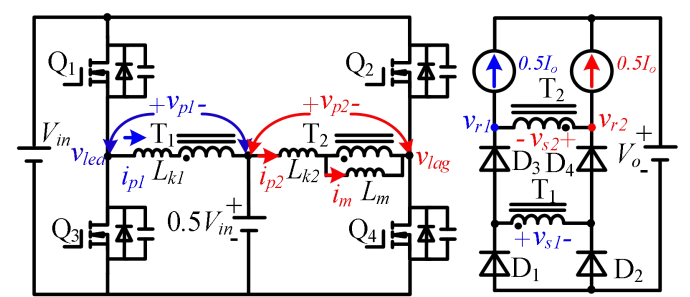

Fig. 3 Equivalent circuit with current and voltage notations.

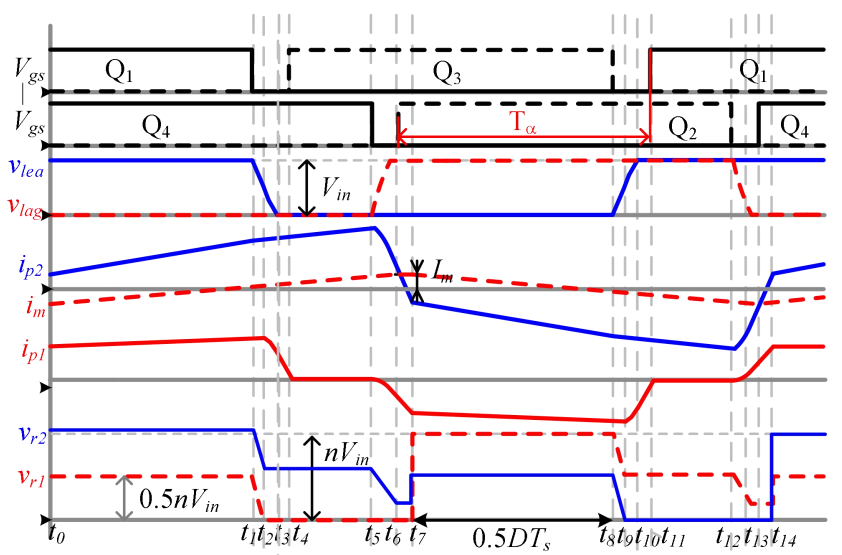

Fig. 4 Key waveforms of Converter \#1 
IEICE Electronics Express, Vol.xx, No.xx, xx-xx

State $1\left[t_{0} \sim t_{1}\right]$ : When switches $\mathrm{Q}_{1}$ and $\mathrm{Q}_{4}$ are in $\mathrm{ON}-$ state and diodes $\mathrm{D}_{2}$ and $\mathrm{D}_{3}$ are conducting, the primary voltages of $\mathrm{T}_{1}$ and $\mathrm{T}_{2}$ are $0.5 V_{\text {in }}$. The rectified voltages $v_{r 1}(t)$ and $v_{r 2}(t)$ are $0.5 n V_{i n}$ and $n V_{i n}$, respectively.

State $2\left[t_{1} \sim t_{2}\right]$ : When switch $\mathrm{Q}_{1}$ turns off at $t_{l}$, the leading-leg current starts to charge the capacitance of $\mathrm{Q}_{1}$ and to discharge the capacitance of $\mathrm{Q}_{3}$. In this state, the leading-leg voltage and the secondary voltage of $T_{1}$ linearly decrease. The diode $\mathrm{D}_{2}$ conducts naturally when the secondary voltage of $\mathrm{T}_{1}$ falls to zero at $t_{2}$.

State $3\left[t_{2} \sim t_{3}\right]$ : Since the secondary voltage of $\mathrm{T}_{1}$ is clamped to zero by $\mathrm{D}_{1}$ and $\mathrm{D}_{2}$ at $t_{2}$, the resonance of the leakage inductances of $T_{1}$ and the junction capacitors of $T_{1}$ and $T_{2}$ occurs in the leading-leg, which results in the sinusoidal deduction of the leading-leg voltage.

State $4\left[t_{3} \sim t_{4}\right]$ : When the leading-leg voltage falls to zero at $t_{3}$, the parasitic diode of $\mathrm{Q}_{3}$ begins to conduct and the ZVS turned-on of $\mathrm{Q}_{3}$ naturally. In this state, the current of the $\mathrm{D}_{1}$ increases and the current of the $\mathrm{D}_{2}$ decreases.

State $5\left[t_{4} \sim t_{5}\right]$ : This state begins when the current of the $\mathrm{D}_{2}$ and the leading-leg current fall to zero at $t_{4}$. In this state, the primary power is transferred to the secondary side only through the lagging transformer. The primary and secondary voltages of $\mathrm{T}_{2}$ are $0.5 \mathrm{~V}_{\text {in }}$ and $0.5 \mathrm{nV}$ in, respectively.

State $6\left[t_{5} \sim t_{6}\right]$ : When $\mathrm{Q}_{4}$ turns $\mathrm{OFF}$ and $i_{m}(t)$ reaches to the maximum value at $t_{5}, \mathrm{D}_{4}$ starts to conduct and the resonance of leakage inductances and junction capacitors occurs in the primary side. The communication between $D_{3}$ and $D_{4}$ is progressed, the current of $D_{4}$ increases and the current of $\mathrm{D}_{3}$ decreases. This state ends when the lagging-leg voltage $v_{\text {lag }}(t)$ reaches to $V_{i n}$.
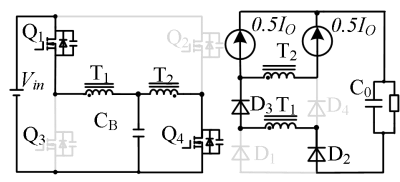

(a)
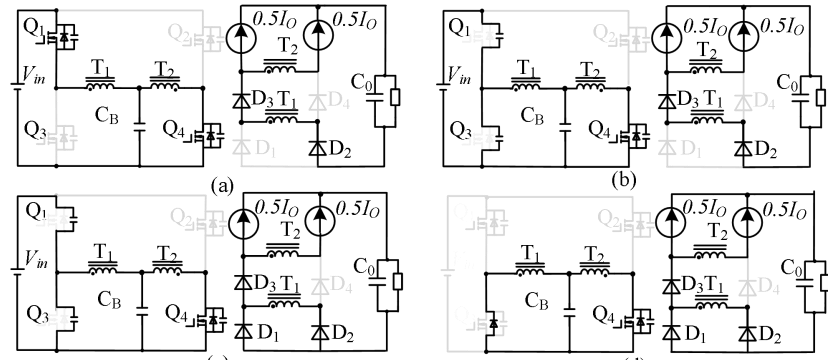

(d)
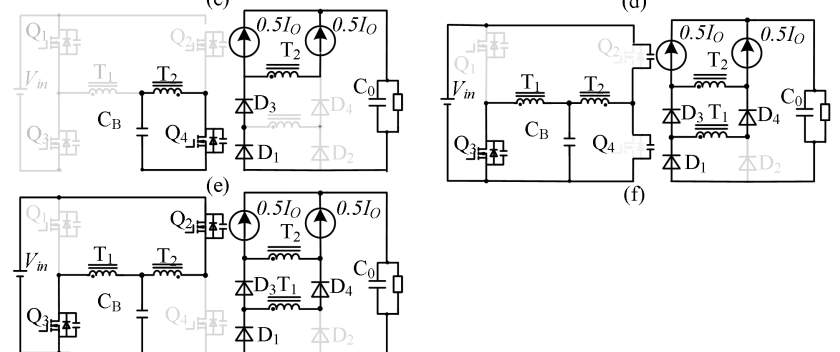

(g)

Fig. 5 Equivalent circuits: (a) State $1\left[t_{0} \sim t_{1}\right]$; (b) State $2\left[t_{1} \sim t_{2}\right]$; (c) State $3\left[t_{2} \sim t_{3}\right]$; (d) State $4\left[t_{3} \sim t_{4}\right]$; (e) State $5\left[t_{4} \sim t_{5}\right]$; (f) State $6\left[t_{5} \sim t_{6}\right]$; (g) State $7\left[t_{6} \sim t_{7}\right]$.
State $7\left[t_{6} \sim t_{7}\right]$ : In this state, $v_{\text {lag }}(t)$ reaches to $V_{\text {in }}$, and the voltage across $\mathrm{Q}_{2}$ falls to zero, which provides favorable conditions to the ZVS of the $\mathrm{Q}_{2}$. The currents of leadingleg and lagging-leg rise in the negative direction because of the existence of voltage across leakage inductances. Besides, the communication between $\mathrm{D}_{3}$ and $\mathrm{D}_{4}$ is continually progressed in the secondary side. When $i_{D 3}(t)$ falls to zero, this state ends up and $\mathrm{D}_{3}$ is naturally turned OFF. The input power transferred from the $T_{1}$ and $T_{2}$ simultaneously to the secondary side.

On account of the symmetric structure of the converter, the next half cycle (State 8 to State 14) are the same as previous states except for the direction of powering path.

\section{Relevant Analysis}

\subsection{Voltage Gain}

Since the switches are controlled with phase-shifted modulation, the voltage gain depends on the shifted time in the proposed converter. The duration of ZVS transitions are so narrow that only the intervals of State 1, State 5 and State 8, State 12 should be considered and the other states can be ignored. Fig.6 shows the simplified waveforms of rectifier voltages. As shown in Fig.6, the rectified voltage in the proposed converter \#1 is a three-level waveform, and the traditional PSFB with CDR is only a two-level waveform. During the dutycycle interval, the rectified voltage is $n V_{\text {in }}$ and the output voltage can be regarded numerically as the average of the rectifier voltage. According to calculation, the voltage gain of the proposed converter $\# 1$ is $0.5 D+0.25$, higher than the voltage gain of the traditional PSFB with CDR. The efficiency will be effectively improved because it is obviously that the high-voltage conversion ratio will not only cut down the secondary-turns number of transformer, but decrease voltage stress of rectified diodes.

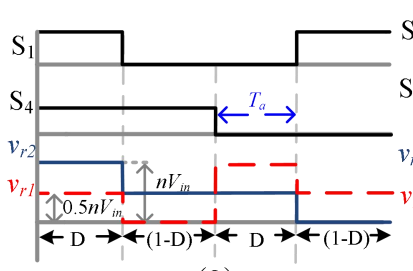

(a)

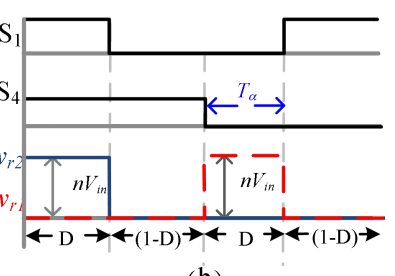

(b)
Fig. 6 Simplified waveforms of rectifier voltages (a) in the proposed converter, (b) in the traditional PSFB converter with CDR.

\subsection{ZVS conditions}

From the operational principle of the proposed converter \#1, the ZVS transition can be divided into the condition of the leading-leg switches and the lagging-leg switches. Firstly, in the leading-leg switches, the ZVS progress can be separated into two parts, State 2 and State 3. In the State 2, the leading-leg current can be regarded as a constant current source and its value is $n I_{o}$. 
IEICE Electronics Express, Vol.xx, No.xx, xx-xx

As a result of the leading-leg, the voltage $v_{\text {lea }}(t)$ decreases in a linear way firstly, and $v_{\text {lea }}(t)$ decreases with a sinusoidal waveform to zero because of the resonance between leakage inductance and junction capacitors. Therefore, at $t_{3}, v_{\text {lea }}(t)$ falls to zero, and the switches can achieve ZVS. Since the remaining energy in the junction capacitors accounts for a quarter of the total energy, the leading-leg switches can implement a wide ZVS range in a easier way. Besides, from the analysis of the laggingleg switches, not only the leakage inductances react on the ZVS transition of lagging-leg, but also they play an important role in the process. When adopting a large magnetizing current, the ZVS range can be extended without sacrificing the primary conduction losses, which different from the obvious conduction loss of all primary components in the traditional converter. At the same time, the lagging-leg switches can use the low-current-rated MOSFETs with small junction capacitors, which is helpful to achieve wider ZVS range and the lower primary conduction losses.

\subsection{Voltage stress of rectified diodes}

For the voltage stress calculation of rectified diodes, the secondary voltage oscillation generated by parasitic circuit element is ignored to simplify the calculation. It is shown that the voltage stress of $\mathrm{D}_{1}, \mathrm{D}_{2}$ and $\mathrm{D}_{3}, \mathrm{D}_{4}$ in the proposed converter $\# 1$ are $0.5 n V_{\text {in }}$ and $n V_{i n}$, respectively. The above analysis indicates that the voltage stress of the proposed converter \#1 is very low. Thus, the lowvoltage-rated diodes can be employed in the topological structure to reduce the power loss and improve the system performance.

\subsection{Performance Comparison}

To help tradeoff design and topology selection in engineering applications, Table I shows the performance comparison among different converters. The proposed converter \#1 and the proposed converter \#3 have the least numbers of secondary components, thus they are more practical for applications. The proposed converters $\# 1, \# 2$ and \#4 employ CDR in the secondary side, and they are well suited for the applications with high output current. For the converters with FBR, the voltage stress of rectified diodes is the smallest and they can be adopted in high output voltage applications. On the contrary, the voltage stress of diodes in the CTR converters is the highest and these converters are preferred to be used in low-voltage applications. As shown in Fig.2, the Hyb-R is composed of a FBR section and a CTR section. As a combined topology, the voltage stress of diodes in the Hyb-R converters is between that of FBR and CTR, which makes them well appropriate for the applications with medium output voltage.
Table 1 Performance comparison among different converters.

\begin{tabular}{|c|c|c|c|c|c|c|}
\hline Converter & $\# 1$ & $\# 2$ & $\# 3$ & $\# 4$ & FBR & CTR \\
\hline$N^{*}$ & $7+2 \mathrm{~W}$ & $9+4 \mathrm{~W}$ & $6+3 \mathrm{~W}$ & $7+3 \mathrm{~W}$ & $8+2 \mathrm{~W}$ & $6+4 \mathrm{~W}$ \\
\hline Voltage gain & $\frac{D}{2}+\frac{1}{4}$ & $\frac{D}{2}+\frac{1}{4}$ & $\frac{D}{2}+\frac{1}{2}$ & $\frac{D}{2}+\frac{1}{4}$ & $\frac{D}{2}+\frac{1}{2}$ & $\frac{D}{2}+\frac{1}{2}$ \\
\hline Stress of diode & $n V_{i n}$ & $n V_{i n}$ & $1.5 n V_{i n}$ & $1.5 n V_{i n}$ & $n V_{i n}$ & $2 n V_{i n}$ \\
\hline Output voltage & High & Low & Medium & Medium & High & Low \\
\hline Output current & High & High & Medium & High & Low & High \\
\hline
\end{tabular}

$N^{*}$ means number of secondary components, $n \mathrm{~W}$ means number of secondary windings.

\section{Experimental result}

Two experimental prototypes based on Fig.2(a) converter \#1 and Fig.2(c) converter \#3 are built to verify the theory analysis since the circuit structures are simple and they are relatively easy to implement. These two prototypes have the same specifications, as follows: input voltage $320 \sim 400 \mathrm{~V}$; output voltage $120 \mathrm{~V}$; maximum output power $1200 \mathrm{~W}$; switching frequency $100 \mathrm{kHz}$.

Fig.7 and Fig.8 show the key waveforms of transformers in the proposed converters \#1 and \#3, respectively. As shown in Fig.7(a) and Fig.8(a), the primary current of $T_{1} i_{p l}$ falls to zero when the ZVS transition of leading switches finish. On the other hand, the primary voltage of $\mathrm{T}_{2} V_{p 2}$ is in phase with the primary current $i_{p 2}$. There is no circulating current in the proposed converters. The primary energy is continuously transferred to the secondary side through $\mathrm{T}_{2}$ during the whole switching period. This feature contributes to reducing the output filter requirement. The experimental results demonstrate the theoretical analysis pretty well.

Fig.9 and Fig.10 show the ZVS waveforms of leading-leg and lagging-leg switches at light load. As seen, all the switches are successfully turned on with ZVS. Therefore, a wide ZVS range can be achieved in the proposed converters.

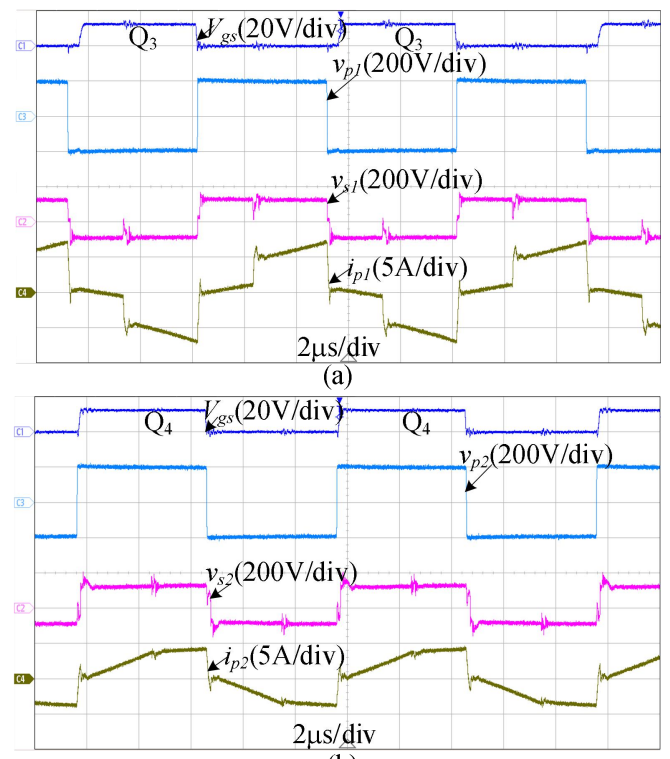

(b)

Fig. 7 Key waveforms of transformers in converter \#1, (a) $T_{1}$; (b) $T_{2}$ 
IEICE Electronics Express, Vol.xx, No.xx, xx-xx

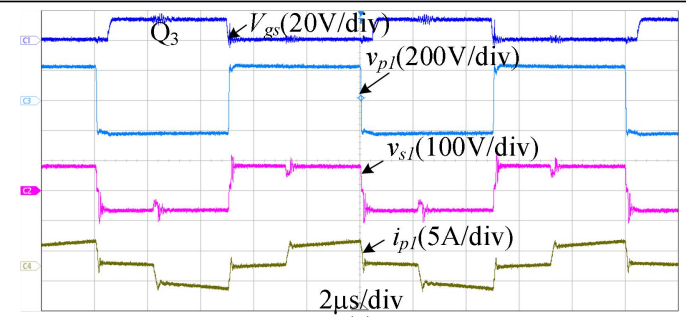

(a)

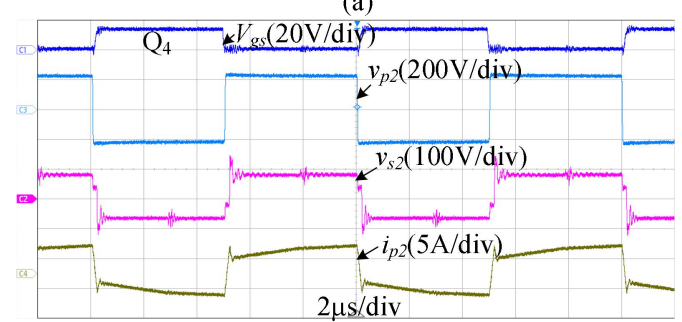

(b)

Fig. 8 Key waveforms of transformers in converter \#3, (a) $T_{1}$; (b) $T_{2}$
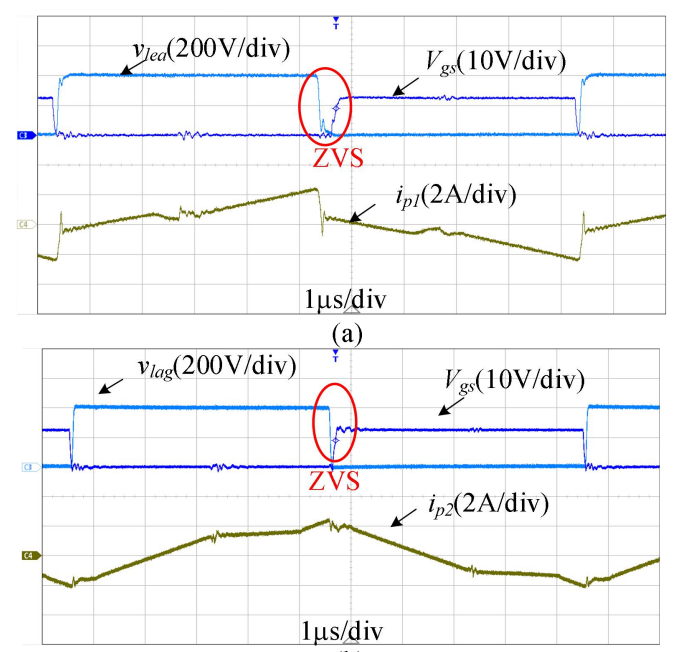

(b)

Fig. 9 ZVS waveforms at light load $I_{o}=2 \mathrm{~A}$ in the converter \#1 (a) Leading-leg switch; (b) Lagging-leg switch.

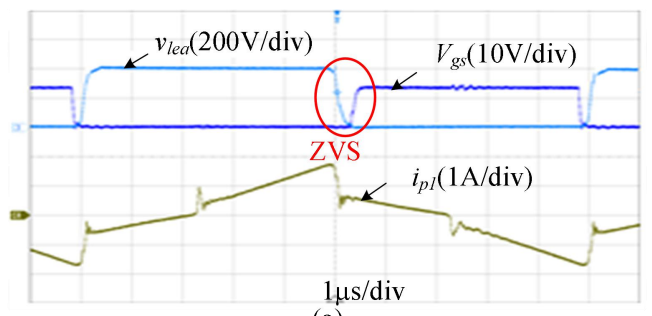

(a)

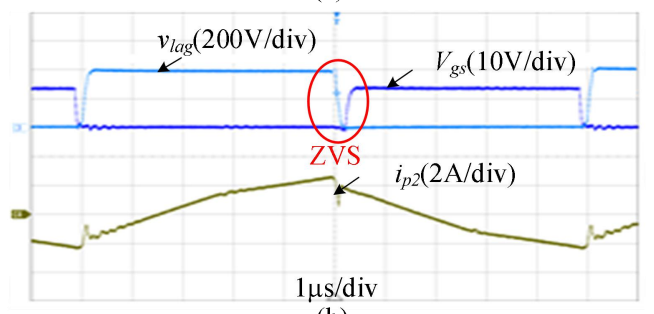

(b)

Fig. 10 ZVS waveforms at light load $I_{o}=2 \mathrm{~A}$ in the converter \#3 (a) Leading-leg switch; (b) Lagging-leg switch.

\section{Conclusion}

In this paper, some novel converters with two transformers are proposed to overcome the disadvantages of traditional PSFB converter such as narrow ZVS range and large output filter requirement. The distinctive characteristics of proposed converters are summarized as follows:

(1) All switches achieve ZVS operation along wide load ranges.

(2) The primary power can be continuously transferred to the secondary side, which contributes to the reduction of output filter requirement.

(3) Various rectifiers can be adopted to suit for different applications.

The theory analysis and performance are fully validated on hardware prototypes.

\section{Acknowledgments}

This work is supported by State Grid Corporation of China (Key parameter design of a DC circuit breaker with adaptive current injected technology, No. 0109300009297-00264).

\section{References}

[1] G. Ranipriya, et al:: "An integrated four port bidirectional dc-dc converter for photovoltaic energy harvesting systems," IEICE Electron. $\quad$ Express. $16 \quad$ (2019) $495 \quad$ (DOI: 10.1587/elex.16.20190495).

[2] L. Zhao, et al.: "A dual half-bridge converter with hybrid rectifier for DC power supply in railways systems," IEEE Trans. Power Electron. 35 (2020) 4579. (DOI: 10.1109/TPEL.2019.2946046)

[3] K. Itoh, et al.: " $28 \mathrm{~W} / \mathrm{cm}^{3}$ high power density three-port DC/DC converter cell for dual-voltage 12-V/48-V HEV subsystem," IEICE Electron. Express. $14 \quad$ (2017) 1 (DOI: 10.1587/elex.14.20170781).

[4] G. Zhang, et al:: "Power electronics converters: past, present and future," Renew. Sustain. Energy Rev. 81 (2018) 2028 (DOI: 10.1016/j.rser.2017.05.290).

[5] U. Badstuebner, et al.: "Optimization of a 5-kW telecom phaseshift DC-DC converter with magnetically integrated current doubler," IEEE Trans. Ind. Electron. 58 (2011) 4736 (DOI: 10.1109/TIE.2010.2103536).

[6] G. Zhang, et al:: "Controllability Analysis and Verification for High-Order DC-DC Converters Using Switched Linear Systems Theory," IEEE Trans. on Power Electronics. 36 (2021) 9678 (DOI: 10.1109/TPEL.2021.3059259).

[7] C.M. Lin and M.C. Li: "Buck-current-fed zero current switching converter for high voltage coupled cavity," IEICE Electron. Express. 9 (2012) 1362 (DOI: 10.1587/ELEX.9.1362).

[8] P. Viriya, et al:: "Analysis of Transition Mode from Phase-Shift to Zero Phase-Shift under ZVS and NON-ZVS Operation for Induction Heating Inverter," IEEJ Trans. on Ind. Electron. 128 (2008) 1317 (DOI: 10.1541/IEEJIAS.128.1317).

[9] Y. Hu, et al.: "Zero-voltage and zero-current switching phaseshifted full-bridge converter with reduced output filter requirement," IEICE Electron. Express. 18 (2020) 440 (DOI: 10.1587/ELEX.18.20200440).

[10] G. Zhang, et al.: "Impedance strengthening and weakening 
IEICE Electronics Express, Vol.xx, No.xx, xx-xx

networks for power converter analysis and design," IEEE Trans. on Power Electronics. $36 \quad$ (2021) 9717 (DOI: 10.1109/TPEL.2021.3063235).

[11] D.S. Gautam, F. Musavi, et al.: "A zero-voltage switching fullbridge DC-DC converter with capacitive output filter for plug-in hybrid electric vehicle battery charging," IEEE Trans. Power Electron. 28 (2013) 5728 (DOI: 10.1109/TPEL.2013.2249671).

[12] A. Shahabi, and A.N. Lemmon, "Modeling of ZVS transitions for efficiency optimization of the phase-Shifted full-Bridge topology," IEEE J. Emerg. Sel. Topics Power Electron. 8 (2020) 529-544 (DOI: 10.1109/JESTPE.2019.2950843).

[13] B. Whitaker et al.: "A high-Density, high-efficiency, isolated onboard vehicle battery charger utilizing silicon carbide power devices" IEEE Trans. Power Electron. 29 (2014) 2606 (DOI:10.1109/TPEL.2013.2279950).

[14] K. Werner, Deboy, et al.: "A power supply achieving titanium level efficiency for a wide range of input voltages," IEEE Trans. $\begin{array}{lllll}\text { Power } & \text { Electron. } & 32 & \text { (2017) } & 117\end{array}$ (DOI:10.1109/TPEL.2016.2532962).

[15] J. Baek, C. Kim, J. Lee, et al.: "A simple SR gate driving circuit with reduced gate driving loss for phase-shifted full-bridge converter," IEEE Trans. Power Electron. 33 (2018) 9310 (DOI:10.1109/tpel.2018.2789340).

[16] C.E. Kim: "Optimal dead-time control scheme for extended ZVS range and burst-mode operation of phase-shift full-bridge (PSFB) converter at very light load," IEEE Trans. Power Electron 34 (2019) 10823. (DOI:10.1109/TPEL.2019.2896322).

[17] T.H. Kim, S.J. Lee, and W. Choi: "Design and control of the phase shift full bridge converter for the on-board battery charger of electric forklifts," Journal of Power Electronics. 12 (2012) 113 (DOI:10.1109/ICPE.2011.5944761).

[18] Y.S. Lai, Z.J. Su and W.S. Chen: "New hybrid control technique to improve light load efficiency while meeting the hold-up time requirement for two-stage server power," IEEE Trans. Power Electron. 29 (2014) 4763 (DOI:10.1109/TPEL.2013.2283747).

[19] X. Wu, H. Chen, J. Zhang, F. Peng, and Z. Qian: "Interleaved phase-shift full-bridge converter with transformer winding seriesparallel autoregulated (SPAR) current doubler rectifier," IEEE $\begin{array}{lllll}\text { Trans. Power Electron. } & \mathbf{3 0} & \text { (2015) } & 4864\end{array}$ (DOI:10.1109/TPEL.2014.2362941).

[20] L.C. Shih, Y.H. Liu, and H.J. Chiu: "A novel hybrid mode control for a phase-shift full-bridge converter featuring high efficiency over a full-load range," IEEE Trans. Power Electron. 34 (2019) 2794 (DOI: 10.1109/TPEL.2018.2838572).

[21] M. Borage, et al.: "A full-bridge DC-DC converter with zerovoltage-switching over the entire conversion range," IEEE Trans. Power Electron. 23 (2008) 1743 (DOI: 10.1109/TPEL.2008.925203).

[22] P.K. Jain, et al.: "Analysis and design considerations of a load and line independent zero voltage switching full bridge DC/DC converter topology," IEEE Trans. Power Electron. 17 (2002) 649 (DOI: 10.1109/TPEL.2002.802181).
[23] Y. Jang, and M.M. Jovanovic: "A new family of full-bridge ZVS converters," IEEE Trans. Power Electron. 19 (2004) 701 (DOI: 10.1109/TPEL.2004.826493).

[24] S.J. Jeon, and G.H. Cho: "A zero-voltage and zero-currentswitching full-bridge DC-DC converter with transformer isolation," IEEE Trans. Power Electron. 16 (2001) 573 (DOI: 10.1109/63.949490).

[25] T.T. Song, and N. Huang: "A novel zero-voltage and zero-currentswitching full-bridge PWM converter," IEEE Trans. Power Electron. 20 (2005) 286 (DOI: 10.1109/TPEL.2004.843016).

[26] J. Wang, B. Ji, H. Wang, N. Chen and J. You: “An inherent zerovoltage and zero-current-switching full-bridge converter with no additional auxiliary circuits," Journal of Power Electronics. 15, (2015) 610 (DOI:10.6113/JPE.2015.15.3.610).

[27] L. Zhao, et al.: "Analysis and design of dual-half bridge converter operating in discontinuous conduction mode," IEICE Electron. Express. 17 (2020) 267 (DOI: 10.1587/elex.17.20200267).

[28] I.O. Lee and G.W. Moon: "Soft-switching DC/DC converter with a full ZVS range and reduced output filter for high-voltage applications," IEEE Trans. Power Electron. 28 (2013) 112 (DOI:10.1109/TPEL.2012.2199520).

[29] I.O. Lee and G.W. Moon: "Analysis and design of phase-shifted dual H-bridge converter with a wide ZVS range and reduced output filter," IEEE Trans. Ind. Electron. 60 (2013) 4415 (DOI:10.1109/TIE.2012.2213564).

[30] K.H. Park and K.H. Yi: "A wide load range ZVS dual half-bridge converters for large-sized PDP sustaining power modules," $J$. Display Technol. 11 (2015) 86 (DOI:10.1109/JDT.2014.2362128).

[31] I.D. Jitaru and N.D. Bolohan: "A high efficiency $2 \mathrm{KW}$ DC-DC converter for automotive application," In Appl. Power Electron. $\begin{array}{llll}\text { Conf. and } \quad \text { Expos. } & \text { (2012) }\end{array}$ (DOI:10.1109/APEC.2012.6165793). 